\title{
Experimental study on unconfined compressive strength of expansive soil improved by lignin and cement
}

\author{
Yuguo Zhang ${ }^{1, \mathrm{a}}$, Weijie Zhang ${ }^{1, \mathrm{~b}^{*}}$, Xiaojie Shi ${ }^{1, \mathrm{c}}$, Tai Guo ${ }^{1, \mathrm{~d}}$, Zhenghao Chen ${ }^{1, \mathrm{e}}$ \\ ${ }^{1}$ School of Civil Engineering and Architecture, Zhongyuan University of Technology, Zhengzhou, Henan, China
}

\begin{abstract}
Aiming at the question of improvement expansive soil in Nanyang area, the composite improvement method of lignin and cement was adopted. Based on the unconfined compressive strength test, the variation law of unconfined compressive strength of improved expansive soil with different lignin content, different compaction degree and different curing age was studied. The test results show that the composite of lignin and cement can effectively improve the unconfined compressive strength of expansive soil. The unconfined compressive strength of L-C (lignin and cement) improved expansive soil reaches the maximum when the cement content is fixed at $4 \%$ and the lignin content is $1 \%$. The unconfined compressive strength of L-C improved soil increases with the increase of compaction degree and curing age, and the strength growth mainly concentrated in the first 7 days of curing age. From the point of improvement mechanism, the hydration and gelation reaction of cement occur in expansive soil, and gel material with higher strength is formed to enhance the strength of expansive soil. The appropriate amount of lignin can fill the pores between soil particles and make the connection between soil particles more closely, so as to improve the strength of expansive soil.
\end{abstract}

\section{Introduction}

Expansive soil is a complex composed of montmorillonite, illite, kaolinite and some primary detrital mineral impurities, it has the engineering characteristics of over consolidation, crack, water absorption expansion softening, shrinkage cracking and repeated deformation[1]. With the rapid development of society, China vigorously advocates the development of the western region, more and more road projects are spread all over the country. These road works must pass through the expansive soil area. Therefore, the improvement of expansive soil is concerned by many soil researchers.

According to statistics, cement has been recognized as a good soil conditioner. Wu Yankai et al. [2], used cement, steel slag powder and $\mathrm{NaOH}$ to test the free expansion rate and unconfined compressive strength of expansive soil subjected to different freeze-thaw cycles. And they obtained that the steel slag powder cement with $\mathrm{NaOH}$ active activator has the most obvious improvement effect. Ruan Bo et al. [3], studied the unconfined compressive strength of cement modified aeolian sand under different curing temperatures, and found that $5 \%$ cement content can meet the design requirements of railway subgrade. Wang Jianli et al. [4], found that epoxy resin and cement can significantly improve the mechanical properties of expansive soil in Anhui Province.

At present, most of the researches on lignin modified soil are focused on silt. Zhang Jianwei et al. [5-6], found that lignin can improve the cohesion, internal friction angle and unconfined compressive strength of silt in the Yellow River flood area. And the unconfined compressive strength is the highest when the lignin content is $5 \%$. Liu Zhaozhao et al. [7], found that the strength of the lignin improved loess increased first and then decreased. And the strength of the improved loess reached the maximum when the lignin content was $1 \%$. They also found that lignin plays an important role in filling soil pores, cementing particles and hydrophobic groups in soil by microcosmic research.

In this paper, lignin and cement were used to improve expansive soil in Nanyang area of Henan Province. Among them, the cement content is based on Yang Jun et al. [8] and according to the index of loaded expansion rate, through the test, it is found that $4 \%$ cement has the best improvement effect on expansive soil, and the cement content is fixed at $4 \%$. Based on unconfined compressive strength test study on expansive soil with different lignin content $(0.5 \%, 1 \% 、 1.5 \% 、 2 \% 、 2.5 \%)$, different degree of compaction $(92 \%, 95 \%, 98 \%)$ and different curing ages $(1 \mathrm{~d}, 7 \mathrm{~d}, 14 \mathrm{~d})$ variation law of unconfined compressive strength of improved soil. The relevant conclusions can be used as reference for engineering practice.

aemail: 240214587@qq.com *Weijie Zhang: bemail: 649748238@qq.com 


\section{Test materials and methods}

\subsection{Test materials}

The soil samples were taken from a lotus field slope in Shigang Town, Neixiang County, Nanyang City, Henan Province. The depth of soil sampling is $1.5 \mathrm{~m}$. The air dried and ground soil sample is shown in Fig.1(a) . Lignin was selected from a material factory in Beishankou Town, Gongyi City, Henan Province. The appearance is as shown in Fig.1(b). The test cement is Tianrui ordinary silicate cement of Zhengzhou City, Henan Province. Its appearance is shown in Fig.1(c), the main chemical components are $\mathrm{CaO}$ and $\mathrm{SiO}_{2}$.

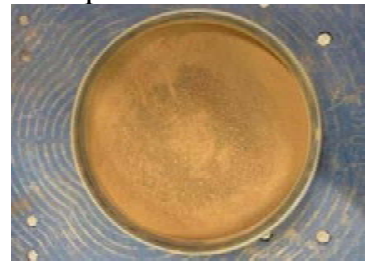

(a)Test soil sample

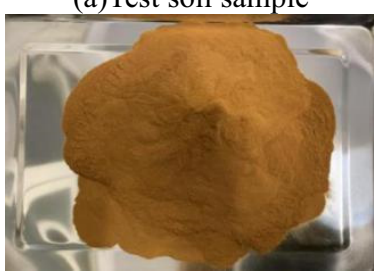

(b)Lignin

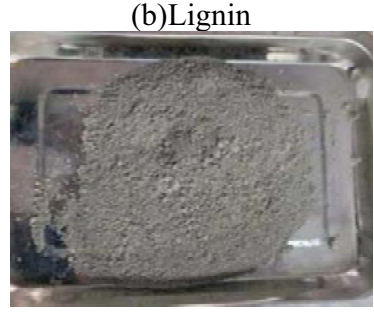

(c)Cement

Fig.1 Test materials

\subsection{Test method}

In order to make the expression more concise. Lignin is replaced by the initial letter $\mathrm{L}$, cement is replaced by the initial letter $\mathrm{C}$.

Unconfined compressive strength test: The specimen is a cylinder with a height of $5 \mathrm{~cm}$ and a diameter of $5 \mathrm{~cm}$. And the test shall be carried out in strict accordance with the code for soil test[9]. Take out the drying soil sample from the oven and add the corresponding proportion of cement and lignin and mix evenly. Then add corresponding water according to the moisture content of $18 \%$ and mix evenly. The soil samples were sealed with fresh-keeping bags all night and static pressure sample preparation with Jack. Two samples were prepared for each group and the test results are averaged.

\section{Test results and analysis}

\subsection{Stress strain curve}

Because the stress-strain curves of L-C improved soil under different curing ages and compactness are similar, only the stress-strain curves with curing age of $7 \mathrm{~d}$ and compactness of $92 \%$ are listed for illustration.

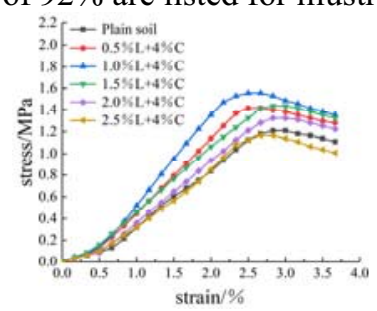

(a) $92 \%$ compaction

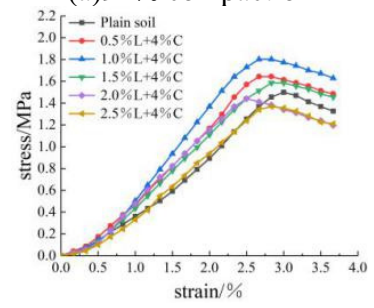

(b) $95 \%$ compaction

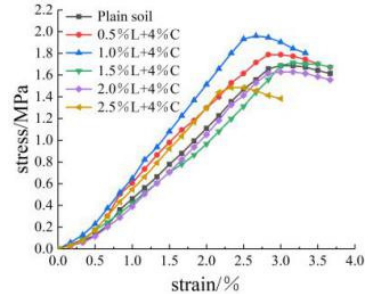

(c) $98 \%$ compaction

Fig.2 Stress strain curve of L-C improved soil at 7d curing

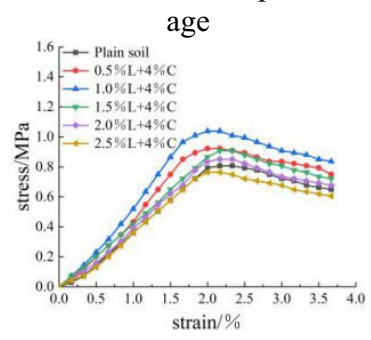

(a)Curing age: $1 \mathrm{~d}$

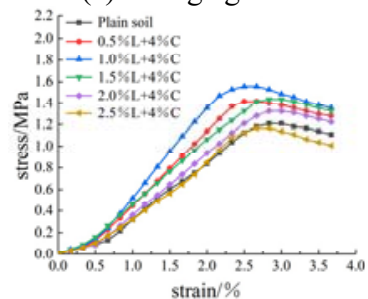

(b)Curing age:7d

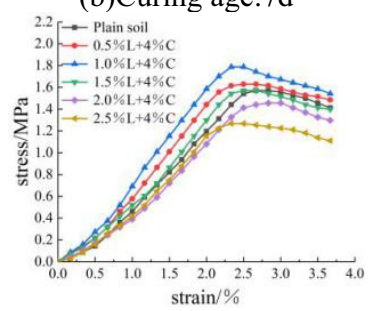

(c)Curing age: $14 \mathrm{~d}$

Fig.3 Stress strain curve of L-C improved soil under 92\% compaction

It can be seen from Fig. 2 and Fig.3 that the stress-strain curve of L-C improved soil has obvious peak. Before the peak, the stress increases linearly with the increase of strain in an $45^{\circ}$ angle. After the stress 
reaches the peak, the stress decreases slowly with the increase of strain. Under the same compaction degree, the failure strain of L-C improved soil is lower than that of plain soil, and the peak stress reached the maximum at $1 \% \mathrm{~L}$. The stress peak point of $1 \% \mathrm{~L}+4 \% \mathrm{C}$ improved soil increases with the increase of compaction degree. The reason is that addition of cement causes hydration and cementitious reactions within the soil to produce higher strength gel substances. It increases the connection between soil particles and makes the soil hardness increase. On the contrary, the toughness becomes weaker. And 1\% lignin fully fills the pores between soil particles and enhances the strength of soil.

\subsection{Unconfined compressive strength}

When the lignin content in the figure is $0 \%$, it represents the pure soil. When the lignin content is other contents, it represents the corresponding amount of $\mathrm{L}+4 \% \mathrm{C}$ improved soil.

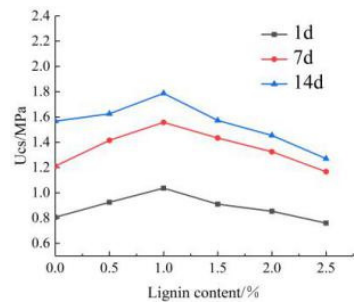

(a) $92 \%$ compaction

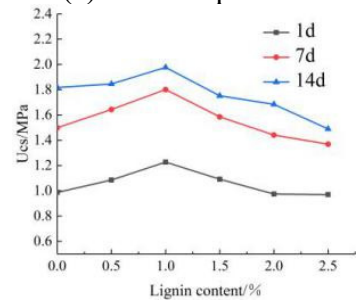

(b) $95 \%$ compaction

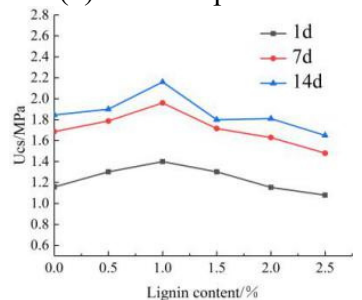

(c) $98 \%$ compaction

Fig.4 Effect of different lignin content and age on improved soil with different compactness

As can be seen from Fig. 4 that the $\mathrm{C}$ content is fixed at $4 \%$, the unconfined compressive strength of L-C improved soil firstly increases and then decreases with the increase of $\mathrm{L}$ content. Under the same compaction degree, the unconfined compressive strength reaches the maximum when $\mathrm{L}$ content is $1 \%$. The unconfined compressive strength of L-C improved soil increases with the increase of curing age. The growth rate was larger in 1-7 days and decreased significantly in 7-14 days. That is to say, the strength increase of L-C improved soil mainly concentrated in the first 7 days. And with the increase of compaction degree, this phenomenon is more obvious.

It can be seen from Fig.5 that the unconfined compressive strength of L-C improved soil increases with the increase of compaction degree. When the compactness is $98 \%$, the unconfined compressive strength reaches the maximum.

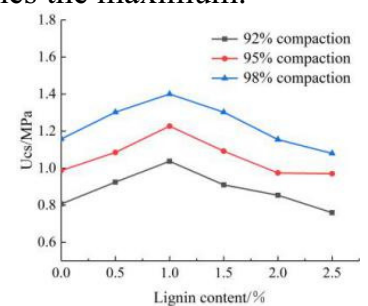

(a)Curing age: $1 \mathrm{~d}$

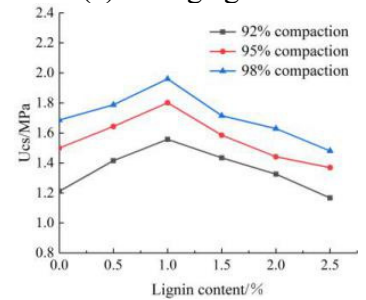

(b)Curing age: $7 \mathrm{~d}$

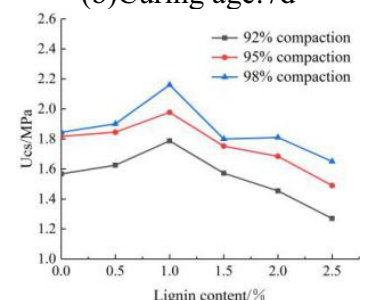

(c)Curing age: $14 \mathrm{~d}$

Fig.5 Effect of different lignin content and compaction degree on different age improved soil

In conclusion, $1 \% \mathrm{~L}+4 \% \mathrm{C}$ can improve the unconfined compressive strength of expansive soil in Nanyang area. The reasons are as follows: Lignin is a polymer with very small particle size. The appropriate proportion of lignin can effectively fill the pores between soil particles, and it enhances the compressive strength of soil. However, excessive lignin content is not conducive to the strength growth of soil. When cement is added into expansive soil, it will produce aggregate action, hard setting reaction and carbonation reaction, then forming cement skeleton to improve compressive strength. The results show that the optimum content of lignin and cement is $1 \% \mathrm{~L}+4 \% \mathrm{C}$.

\section{Conclusion}

Through the experimental study on unconfined compressive strength of expansive soil improved by lignin and cement composite, the following conclusions can be obtained:

(1)When the cement content is fixed at $4 \%$, the unconfined compressive strength of L-C improved soil firstly increases and then decreases with the increase of lignin content from $0 \%$ to $2.5 \%$. When the lignin content is $1 \%$, the unconfined compressive strength of L-C improved soil reaches the maximum.

(2)The unconfined compressive strength of L-C improved soil increases with the increase of compaction degree and curing age. And the increase of unconfined compressive strength mainly concentrated in the first 7 
days.

(3)Through unconfined compressive strength test and comprehensive consideration of various factors, the optimal content of lignin and cement is $1 \% \mathrm{~L}+4 \% \mathrm{C}$.

\section{Acknowledgments}

This work was financially supported by the Key Scientific Research Projects of Colleges and Universities in Henan Province in 2019 (19A560027).

\section{References}

1. Han, J., Wang, L.H., Ma, L., Yang, C. (2015) Effect of cement and lime content on shear strength of improved expansive soil. J. Yellow River., 37(04): 137-139+144 (in Chinese).

2. Wu, Y.K., Miao, S.Y., Li, X., Wang, H., Cao, Y.P., $\mathrm{Hu}, \mathrm{X} . \mathrm{T}$. (2020) Laboratory test on expansive soil improved by steel slag powder and cement under freeze-thaw cycle. J. Journal of engineering geology., 1-12 (in Chinese).

3. Ruan, B., Zheng, S.L., Zhang, X.J., Ding, H., Nie, R.S., Ruan, C.X. (2020) Experimental study on unconfined compressive strength of cement modified aeolian sand under low temperature curing condition. J. Journal of Railway Science and Engineering., 1-9 (in Chinese).
4. Wang, J.L., Zhang, J.M., Mi, M., Zhou, Z., Luo, Y., Yuan, C. (2019) Experimental study on expansive soil reinforced by epoxy resin cement composite. J. Yellow River., 50(10): 209-215(in Chinese).

5. Zhang, J.W., Wang, X.J., Li, B.B., Han, Y., Bian, H.L. (2020) Experimental study on consolidation of silt with EICP lignin. J. Journal of civil and environmental engineering., 1-2 (in Chinese).

6. Zhang, J.W., Kang, F.X., Bian, H.L., Yu, H. (2020) Experimental study on unconfined compressive strength of silt improved by lignin under freeze-thaw cycles. J. Geotechnical Mechanics., 2020(S2): 1-6 (in Chinese).

7. Liu, Z.Z., Wang, Q., Zhong, X.M., Liu, F.Q., Liang, S.Y., Gao, Z.N. (2020) Water holding capacity and water stability of loess improved by lignin. J. Journal of rock mechanics and Engineering., 1-11 (in Chinese).

8. Yang, J., Xu, W., Zhang, G.D., Tang, Y.W., Chen, H.P. (2014) Improvement effect of different materials on expansive property of Yichang weak expansive soil. J. Journal of Xinyang Normal University(NATURAL SCIENCE EDITION), 27(01): 149-152 (in Chinese).

9. SL 237-1999. (1999) Code for geotechnical test. China Water Conservancy and Hydropower Press, BeiJing. 